\title{
El asociacionismo marinero en el litoral español: la Federación Nacional de Industria Pesquera de la CNT
}

Dionísio Pereira

\section{Introducción}

El presente trabajo tiene por objetivo enmarcar la constitución (1931) y particular recorrido de la Federación Nacional de Obreros de la Industria Pesquera y sus Derivados (FNIP) de la Confederación Nacional del Trabajo, tomando como referente organizativo dentro de la central anarcosindicalista a la Federación Regional Galaica de Industria Pesquera y sus Derivados (FRGIP), que la precedió en el tiempo, y a Galicia, región pesquera española por excelencia, como referente territorial. Y decimos particular en lo orgánico, porque fue la Federación de Industria de la CNT que más trató de desarrollar una visión de industria superadora de los oficios o gremios, incluyendo tanto a pescadores como a las trabajadoras de las fábricas de conserva, a los pequeños patrones transportistas de pescado y, con ciertas condiciones, a los pequeños armadores. La aparición e implantación mayoritaria de ambos organismos en Galicia, un territorio periférico alejado de las grandes concentraciones proletarias terrestres del Estado español y con una composición social específica, confieren, asimismo, una llamativa singularidad al sindicalismo pesquero de clase en la costa gallega y española.

\section{Contexto: de la pesca artesanal al capitalismo pesquero}

La conciencia de la dura condición del trabajador del mar estará en el inicio del instinto asociativo que, avanzando el siglo XIX, entronca con los Gremios de Mar medievales. Pero el asociacionismo marinero desenvuelto en el primer tercio del siglo $\mathrm{XX}$ va a progresar en un panorama cambiante en cuanto a las actividades pesqueras.

Como se sabe (Giráldez Rivero, 1989), en el transcurso de este período, los pescadores gallegos pasan de faenar estacionalmente a pocas millas de la costa procurando mayormente sardina y merluza, a bordo 
de pequeñas embarcaciones impulsadas a vela y remo de propiedad familiar, a tripular una flota de vapores, que, tras esquilmar los bancos de pesca tradicionales, frecuentaba caladeros distantes y atendía a las crecientes necesidades urbanas de un consumo masivo de pescado fresco. En realidad, se estaba produciendo un cambio estructural en la pesca, derivado de un cambio del modo de producción pesquero. Dicho de otra manera, en aquel tiempo se vivió la transición entre la pesca artesanal y el germinar del capitalismo en el sector extractivo, inducido ya por el desarrollo acelerado de las actividades de transformación del pescado, ahora verdaderas dominadoras del mercado de la sardina, ya por la demanda urbana de pescado de mesa alentada tras la mejora de las comunicaciones ferroviarias y por carretera.

Para que tengamos un punto de referencia y siguiendo las estadísticas oficiales de pesca, en 1932 la flota gallega estaba compuesta por 14.161 embarcaciones, que desplazaban 60.000 TRB, capturaban 127.000 tons. de pescado y tenían como dotaciones 58.000 hombres, con la particularidad de que el $70 \%$ del tonelaje y el $49 \%$ de las tripulaciones correspondía ya a barcos de propulsión mecánica. Grosso modo, la flota pesquera gallega representaba la tercera parte de la española, tanto en número de buques como de tripulantes. ${ }^{1}$

En el litoral, no obstante, convivirán hasta hoy los dos modelos antedichos: el de la pesca artesanal, vinculada al espacio familiar, y lo que podriamos denominar de transición a la pesca industrial o al capitalismo pesquero, ejemplarizada en la diversidad de actividades extractivas y derivadas del puerto de Vigo-Bouzas, única experiencia industrial estructurada en la Galicia de anteguerra.

En lo tocante al modelo artesanal, el objetivo fundamental de la pesca era abastecer las necesidades familiares, empleando una tecnología tradicional para faenar en caladeros próximos a la costa, con unas relaciones de producción definidas por un mitigado antagonismo entre patrones/armadores y marineros, que compartían las labores extractivas y una distribución relativamente equitativa del producto (Delgado Cendagortagalarza, 1998). Por el contrario, el incipiente capitalismo pesquero desarrollado desde finales del siglo XIX en los principales puertos de pesca españoles (Vigo-Bouzas, Pasaia, Coruña, Gijón, Cádiz, Algeciras, Barcelona, Santander, por este orden) tenía como finalidad la maximización de beneficios para amortizar unas voluminosas inversiones, que posibilitaban la introducción de barcos con propulsión mecánica y una tecnología que intensificaba las capturas en caladeros cada vez más lejanos del litoral. En estas embarcaciones, además, se desarrollaron 1933. 
unas relaciones sociolaborales caracterizadas por un mayor antagonismo y desigualdad, simbolizadas tanto por el control de los nuevos medios de producción en pocas manos, como por el endurecimiento de las condiciones de trabajo y un reparto del producto menos equitativo que en la pesca artesanal (González Laxe, 1977).

Después de la Primera Guerra Mundial y hasta bien entrada la Segunda República (1931-36), el acelerado crecimiento de la pesca industrial tanto en el Cantábrico como en el litoral Sur-Atlántico, debido a su rápido acceso a nuevos caladeros (Grand Sole, en el Norte; Banco Canario-Sahariano, al Sur) y potenciales mercados, o a las estrategias de los armadores sabedores de las diversas condiciones sociolaborales existentes en los distintos puertos, dio lugar al desplazamiento de muchos armadores y marineros gallegos tanto a localidades norteñas caso de Gijón (Asturias) y Pasaia (Euskadi), como del Sur, caso de los puertos andaluces de Huelva, Algeciras y, sobre todo, Cádiz (Giráldez Rivero, 2002). Por aquel entonces, pues, empezaron a conformarse colonias de pescadores gallegos en dichos puertos, algunas de ellas persistentes hasta hoy.

En ese período, la localidad vasca de Pasaia fue escenario de una industria pesquera en acelerado desarrollo que, en el albor de los años 30, rivalizaba con Vigo por ser el mayor puerto pesquero del Estado español (Colectivo Xerminal, 1990). Con la particularidad de que la flota de superior tonelaje dedicada al arrastre de altura recalaba no en la dársena viguesa del Berbés, sino en los recientes "docks" pasaitarras de La Herrera (Barkham Huxley y López Losa, 1999).

\section{La fuerza de trabajo. Nuevas relaciones de producción}

Se puede decir que, en la costa gallega, el tránsito del modo de producción artesanal a un capitalismo pesquero más o menos desarrollado fue visible en muchas villas costeras en torno a la Primera Guerra Mundial. Al igual de lo que ocurriera entre siglos, primero en Vigo y luego en Coruña, después en Marín, Cangas, Moaña, Bueu, Baiona, Cariño, Celeiro o Ribeira, observaban cómo los tripulantes de las embarcaciones tradicionales eran absorbidos por los vapores y motoras, y también cómo la pesca con los aparejos artesanales era sustituida por las capturas masivas de los cercos, los palangres de fondo y el arrastre con el "bou" (en inglés "trawler") o en pareja.

Como se apuntó, en los nuevos barcos los tripulantes soportaron unas relaciones laborales bien distintas del paternalismo propio del Antiguo Régimen ${ }^{2}$. De inicio, muchos armadores que concentraban

2. Aunque hay autores como José Filgueira Valverde que idealizan este paternalismo 
dotaciones de 30 o 40 hombres en sus vapores y motoras dejaron de ir al mar, quedando escindido el colectivo pesquero. Además, los trabajos de la pesca intensiva se hicieron más penosos en las, a partir de ahora, largas mareas, ya que no habia correspondencia entre las grandes dimensiones de las nuevas artes y el mayor volumen de las capturas, con la pequeña potencia de los primeros dispositivos mecánicos de virada. Entonces, la única solución era tener más brazos a bordo, agravando las condiciones de habitabilidad, ya espartanas, de los buques.

En el nuevo modelo pesquero las tareas de tierra requirieron, también, más tiempo, mayor esfuerzo y, por consiguiente, demandaron mejor retribución. Fijémonos en Marín, por ejemplo; allí los vapores pareja de arrastre del día faenaban 14 horas y habia que contar, a mayores, con las labores de tierra: descargar los pesados aparejos y teñirlos cada 15 días; lavar las redes cada dos o tres; acarrear agua; palear carbón y acomodarlo en las carboneras; reparar los aparejos... En 1910 no amarraban ni los domingos: la bajada de los barómetros y las fiestas patronales decidian las recaladas. El pago de tantos trabajos era, en el momento, 90 pesetas por mes, sin que los trabajos de tierra tuvieran retribución alguna; luego venían, desde los 50 años, el cuerpo deshecho y la tisis como algo habitual (Maná, 1994).

En algunos barcos la manera de retribuir también cambió: en los "trawlers" y en las parejas de arrastre se introdujo a comienzos del siglo XX el pago a jornal, diferenciado entre los simples marineros, el personal de máquina y los patrones. En el resto de los oficios persistió el tradicional reparto en "quiñones", se bien ahora en las motoras sardineras el porcentaje a percibir fue tanto más favorable al armador, conforme el capital invertido en la embarcación y en los aparejos fuese mayor. A esta desigualdad en el reparto se unirá la certeza de que los armadores pretenderán en adelante descontar las innovaciones introducidas en los barcos (las primeras maquinitas de vapor para virar, por ejemplo) de las partes de los tripulantes, o remolonear en el pago de las faenas en tierra, provocando que muchos marineros de la bajura retribuidos "a la parte" tomasen conciencia de su condición de desposeídos, a pesar de no estar sujetos al salario.

La confrontación, pues, acompañó a la transición pesquera; una conflictividad que va a estar presente durante el periodo en todos los estadios del ciclo productivo tendrá múltiples consecuencias en las relaciones sociales de los distintos puertos y será especialmente visible en el caso de la pesca de la sardina y en la pesca de arrastre. Y como la función

más o menos igualitario desenvuelto en una pretendida "cristiana y equitativa economía comunal de los cercos" gremiales, el profesor Xan Carmona demostró la existencia de antagonismo y desigualdad social ya en los Gremios de Pescadores del Medievo (véanse Carmona, 1998, y Filgueira Valverde, 1946). 
hace al órgano, el proceso (conflictivo) de cambio también vino acompañado por la eclosión del asociacionismo en el sector, representativo de las diversas capas del colectivo marinero, cada vez más conscientes de sus intereses y organizadas para su defensa, en un proceso que llega a su cenit durante la Segunda República.

\section{Evolución del asociacionismo marinero de clase (1899-1925)}

La introducción y desarrollo del capitalismo pesquero en Vigo-Bouzas, en Coruña y, tímidamente, en Marín allanó, ya en la década final del siglo XIX, el camino para la génesis de las primeras sociedades de resistencia en la pesca. En 1899, al mismo tiempo que se producía una huelga por divergencias en torno a las bases de trabajo, los tripulantes de los vapores palangreros con base en el muelle vigués del Berbés constituyeron su Sociedad de Marineros-Pescadores, la federaron en la organización obrera local de carácter socialista y animaron a los marineros que iban "a la parte" a integrarse en ella; al poco tiempo, se crea la Sociedad de Obreros Pescadores de Bouzas en estrecha relación con las agrupaciones proletarias viguesas. Esta primera organización de clase en el mar provocará de inmediato la aparición en Vigo-Bouzas de la primera Patronal pesquera organizada en Galicia, la Sociedad Marítima de la Villa de Bouzas, un colectivo de largo recorrido conocido como La Maritima (Giráldez Rivero, 1984).

En torno a la Primera Guerra Mundial, el espectacular crecimiento de la flota de arrastre en pareja en los puertos de Bouzas y Marin, sumado a la introducción de motores de explosión que posibilitaban la persecución de los bancos de sardina hasta aguas portuguesas, mudaron las relaciones laborales en la mayoria de las "villas sardineras" de las Rías del Sur de Galicia y dieron pie a la implantación allí del sindicalismo de clase. Así, entre 1913 y 1920 se producirá entre los tripulantes de vapores y motoras con base en aquel litoral una notoria agitación, que cristaliza durante la Guerra Mundial en la constitución de las respectivas Alianzas Marineras de Marin, Cangas, Moaña, Chapela y Pontevedra; todas ellas, estarán en mayor o menor medida en la órbita de la socialista Unión General de Trabajadores e integrarán en sus filas a los pequeños patrones/armadores, una práctica que tendrá continuidad hasta la Guerra Civil (Santos Castroviejo y Nores Soliño, 2005).

Coincidiendo con la Revolución Rusa, las reivindicaciones sobre incremento de las dotaciones, salarios y "partillas", retribución de las tareas de tierra, etc., defendidas a principios del siglo en los grandes puertos de Vigo y Coruña, se extenderán y provocarán una intensa conflictividad en las calles de Marín, Moaña, Bueu y Cangas. En este 
contexto, a partir de 1915 funcionará una ambiciosa Federación Regional de Obreros de la Industria Pesquera de Galicia radicada en Marin, que integraba sociedades de marineros, maquinistas y patrones. Alentada por militantes socialistas, la Federación fue el primer germen de coordinación del sindicalismo marinero de clase en Galicia y será reorganizada cinco años más tarde bajo la denominación de Comité Regional de los Obreros de la Industria Pesquera y Derivados de Galicia.

En el otro extremo del espectro social, también hubo novedades. Incentivadas por el auge del sindicalismo, nacerán en Vigo dos entidades patronales de largo aliento: la Sociedad de Armadores, Vendedores y Exportadores La Necesaria, domiciliada en O Berbés y constituida al finalizar 1916, y la Asociación General de Industrias Pesqueras y sus Derivadas concebida como "lobby" económico de ámbito galaico en octubre de 1917; el colectivo representaba dos años más tarde a los armadores de 202 vapores y los propietarios de 43 fábricas de conserva y salazón de quince puertos del litoral gallego que empleaban más de veinte mil marineros y operarias de las fábricas de conserva (Giráldez Rivero, 1996).

A estas alturas, los armadores, las autoridades y la Iglesia Católica recelaban de la extensión del societarismo clasista. En consecuencia, comenzó a desarrollarse, propiciada por el aparato del Estado, la propuesta conciliadora de los Pósitos Pescadores. Inspirados en las Cofradias del Antiguo Régimen, se definían como asociaciones cooperativas sin distinción entre armadores y marineros, que procuraban mejorar las condiciones de vida del colectivo pesquero mediante el establecimiento de socorros y seguros, la promoción del cooperativismo, la dotación de infraestructuras y la extensión cultural entre los asociados. Los Pósitos estaban financiados, además de las cuotas de los socios, por los créditos procedentes de la Caja Central de Crédito Marítimo dependiente del Ministerio de Marina, que vehiculizaba el intervencionismo estatal. La composición de sus órganos representativos era paritaria, adoptando un talante corporativo, moderado y sumiso a las autoridades, que intentaba conciliar los intereses de armadores y marineros, apartando a éstos de las organizaciones de clase. Sustentados en el tejido social de la pesca artesanal de base familiar, los Pósitos tuvieron un fuerte incremento en la Dictadura de Primo de Rivera (1923-30), debido a su buen acomodo en el corporativismo social que pretendió implantar aquel régimen político. Llegada la Segunda República, en el litoral español existían 199 Pósitos y un total de 29.593 asociados, un $25 \%$ de ellos pertenecientes a los 60 Pósitos gallegos (Ansola Fernández, 2007). 


\section{Federación Regional Galaica de Industria Pesquera y sus Derivados: antecedentes}

Retornando al sindicalismo, en la costa coruñesa y contando con una presencia mayoritaria de los anarcosindicalistas integrados en la Federación Local Obrera de A Coruña, nacía a finales de 1914 uno de los colectivos más longevos y representativos de la CNT herculina: la Sociedad de Marineros, Fogoneros y Patrones El Despertar Marítimo, que incorporaba a sus filas tanto los tripulantes de la marina mercante y de servicio de puerto, como las tripulaciones de los buques de pesca retribuidos a jornal.

Con anterioridad a 1920, El Despertar se dedicó de manera prioritaria a regular las condiciones laborales de los marinos mercantes, cuya seguridad en el empleo estaba amenazada tanto por las incidencias de la Gran Guerra, como por la masiva venta de barcos a las naciones contendientes. Las aspiraciones de los marinos en aquellos bélicos dias se resumian en la oposición a la venta referida, la creación de un Montepío para posibilitar el cobro del retiro, la dotación por parte del Estado de centros de capacitación profesional y la reglamentación por ley de los trabajos a bordo. ${ }^{3}$

Con el transfondo de los ataques a barcos mercantes de bandera neutral, este abanico reivindicativo dio lugar entre 1914 y 1918 a una multitud de conflictos laborales en toda la costa española, alentados por un conjunto de colectivos de carácter socialista o libertario, que incorporaban al personal subalterno tanto de la mercante como de la pesca. En ese clima de confrontación, los trabajadores del mar organizados en el puerto de A Coruña participaron de manera señalada en la creación de una Federación de Obreros de la Navegación y Transporte de España de carácter unitario, que integraba sociedades de marineros, fogoneros y maquinistas, así como de estibadores en varios puertos del Estado. ${ }^{4}$ Las sesiones constituyentes se celebraron en septiembre de 1915 en la Casa del Pueblo de Bilbao; alli quedó establecido un equilibrio de fuerzas entre socialistas y libertarios y se dejó en libertad a las secciones para decidir si empleaban o no los organismos de mediación denominados Juntas Locales de Reformas Sociales. ${ }^{5}$ El Congreso atendió, además,

3. Hoja volandera de El Despertar Maritimo de A Coruña, datada el 8/3/1917.

4. Esta Federación fue heredera de la Federación de Fogoneros, Marineros y Obreros Similares de España, creada en Barcelona en el año 1902 y que en 1906 declaraba tener 9.380 asociados, distribuidos en 35 Secciones (España Marítima y Pesquera, Madrid, febrero de 1936).

5. Mientras los libertarios, partidarios de la acción directa, rechazaban la participa- 
las reclamaciones relativas al jornal y al descanso de los tripulantes de aquellos vapores pesqueros mayores de 25 tons.

El importante papel jugado por los coruñeses en la susodicha Federación quedó de manifesto cuando, en mayo de 1917, un nuevo congreso organizado en Barcelona decidió que la secretaría se trasladase a la capital gallega, para ser regentada por el tipógrafo anarcosindicalista Juan Nó Iglesias, que a la sazón era presidente de la potente Federación Local Obrera. Al congreso asistieron delegados de 8.000 marinos mercantes, estibadores y pescadores a jornal, integrados en 18 sociedades de resistencia radicadas en otros tantos puertos del litoral español. ${ }^{6}$ Finalizada la guerra, muchas sociedades federadas se afiliarán a la CNT, caso de la asturiana Unión Marítima de Gijón, en un ambiente de fuerte conflictividad en la marina mercante y franca desunión entre los partidarios de la UGT y la CNT, algo que provocará la desaparición de la organización nacional a partir de 1920 (Bar, 1981; Zamora Terrés, 2003). Por otra parte, y debido al auge que cobrará la pesca a bordo de los barcos movidos por propulsión mecánica a partir de los años 20, en adelante las propuestas organizativas para los trabajadores de la mercante y de la pesca tomaron rumbos distintos.

La visión sectorial, superadora de los oficios, fue aprobada en el congreso de la CNT celebrado al final de 1919. Al socaire de las decisiones congresales enfocadas hacia la organización de los sindicatos de industria, en el muelle coruñés se consolidará esta nueva concepción sindical un año después, pues El Despertar Marítimo se convertirá en Sección del Sindicato Único del Transporte Marítimo y Terrestre, que agrupaba todas las profesiones relacionadas con las tareas portuarias. Consciente de su poderío, manifestado en 1920 con el paro de las parejas de arrastre que descargaban en Coruña prolongado durante cinco meses, la organización herculina empezó a presionar a los tripulantes de aquellos arrastreros matriculados en Marin y Bouzas pero que tenian base en Coruña, para que se diesen de baja en la UGT y se incorporasen a la CNT, iniciando unas disputas que ni siquiera la dictadura de Primo pudo cortar.

Los últimos plenos del Comité Regional de Obreros de la Industria Pesquera de Galicia y Derivados reflejarán la tensión, de manera que una asamblea de este colectivo celebrada en el año 1922 en Pontevedra y a la que asistieron 22 secciones, exigió a los libertarios coruñeses el reconocimiento de las sociedades afiliadas al Comité (Santos Castroviejo y Nores Soliño, 2005). Un año después, se puso en cuestión la hegemo-

ción institucional, los socialistas eran proclives a utilizarla (Boletín del Instituto de Reformas Sociales, Madrid, octubre de 1915).

6. Solidaridad Obrera, Barcelona, 31 de mayo y 2 de junio de 1917. 
nía socialista en la villa de Marín, tras el diligente apoyo de la CNT a la huelga de los tripulantes de las parejas en favor del descanso semanal. ${ }^{7}$ Y lo que fue más importante, la Sección Flota Pesquera integrada desde 1922 en el anarcosindicalista Sindicato General de Trabajadores de Vigo, comenzó a disputar la tradicional influencia socialista en aquella ria, apoyado en la potente organización coruñesa.

Con la llegada de la gris etapa de la dictadura, el clima represivo provocó el decaimiento del societarismo marinero en las pequeñas localidades costeras, sin que los sindicatos de clase dejaran de funcionar en los grandes puertos. Así, en el primer año del nuevo régimen se producirá una dura competencia por el control del puerto de Vigo-Bouzas entre el Sindicato General de Trabajadores y el Comité Regional de Obreros de la Industria Pesquera de Galicia y Similares, conscientes cenetistas y socialistas de su importancia como centro de aprovisionamiento, de las descargas de pescado y de la contratación del personal. Al final, la CNT impuso su hegemonía y mejor organización en el muelle coruñés, donde descargaban y repostaban numerosas parejas de Bouzas, de manera que muchos asociados a la UGT en este último puerto solicitó en el año 1925 su integración en la Sección Flota Pesquera, tras las gestiones del fogonero coruñés Manuel Montes Don, presidente de El Despertar Marítimo. ${ }^{8}$

Desaparecido el Comité Regional a partir de 1925, contando con una fuerte influencia en los puertos de Coruña, Bouzas y Vigo, y ayudados por cuadros societarios de Ferrol, Ribeira y Marin, que estaban desorganizados por la presión gubernativa, los anarcosindicalistas articularon en aquel año la Federación Regional Marítima, con la idea de agrupar todas las profesiones vinculadas al mar. La asamblea constituyente tuvo lugar en Compostela el día 6 de diciembre; a ella asistieron, entre otros, el entonces secretario de la Confederación Regional Galaica (CRG) de la CNT, Manuel Fandiño; el director del periódico Solidaridad Obrera, Ezequiel Rey; Manuel Montes, por El Despertar Marítimo de Coruña y José Villaverde Velo, por Vigo-Bouzas. Además del acuerdo de crear la Federación, tuvo importancia el debate sobre su carácter "nacional" o "regional". Al final, se adoptó la propuesta de Villaverde, consistente en que:

...por el momento debe ser regional con aspiraciones de nacional, y creada la federación maritima gallega, con hechos se les

7. Galicia, Vigo, 18/4/23.

8. Solidaridad Obrera, Santiago, 29/8/25. 
puede demostrar a las demás regiones las ventajas que tiene la organización. ${ }^{9}$

Con sede en Coruña, la referida Federación se legalizó al año siguiente bajo el rótulo de Federación Regional Galaica de la Industria Pesquera y sus Derivados (FRGIP), y tuvo durante toda la etapa de la dictadura a Montes como secretario y a Villaverde, liberado de la Sección Flota Pesquera viguesa, como encargado de la redacción de su vocero El Despertar Marítimo. ${ }^{10}$ Finalizaban así más de cinco años de trabajos para organizar la Federación pesquera confederal, pues la estrategia ya fuera anunciada en el año 1919 durante el Congreso de la CNT. La FRGIP fue, por lo tanto, precursora de la futura estructuración de la CNT en federaciones de industria, decidida seis años más tarde en el Congreso de 1931, y también antecesora de la Federación Nacional de Obreros de la Industria Pesquera y sus Derivados (FNIP), conformada en 1931.

En suma, la FRGIP pudo conservar una mínima estructura en Coruña, sostenida por El Despertar Maritimo; este colectivo, sorteando la presión gubernativa que llegó a clausurarlo temporalmente y mandó a Montes a prisión en el año 1928, desarrolló una actividad continua en reivindicación del descanso dominical en la pesca de arrastre. Por consiguiente, la CNT galaica contó con un armazón sindical en el mar que se demostraría muy útil de cara a la difusión societaria, cuando la descomposición del régimen posibilitó la reorganización de la totalidad del sindicalismo marinero de clase.

\section{Superación del localismo por parte de las patronales pesquera y conservera}

Paralelamente al itinerario recorrido por el sindicalismo marinero, la estrategia de los armadores organizados fue procurar la expansión territorial y el reforzamiento solidario de los distintos colectivos patronales, alentando organismos más allá del ámbito local, siempre desde una defensa numantina del derecho "natural" atribuido a los propietarios de los medios de producción en relación a la admisión y el despido del personal en los barcos, rechazando de plano el control societario en esta cuestión.

Visto con perspectiva, si bien es perceptible que la combatividad y la

9. Oficio fechado el 30/12/1925; Fondo Goberno Civil de A Coruña, Asociacións, A Coruña, Carpeta El Despertar Marítimo, Arquivo Reino de Galicia (ARG), A Coruña.

10. La Federación Regional Galaica de la Industria Pesquera y sus Derivados figura inscrita en el año 1926, Fondo Goberno Civil de A Coruña, Asociacións, A Coruña, Carpeta G-2657/13, ARG. 
capacidad organizativa de las sociedades marineras en las rías de Pontevedra y Vigo medra de manera ostensible durante la Primera Guerra Mundial, no lo es menos que las patronales de ese litoral representaban ya en aquel tiempo una fuerza social de primer orden, que tenía superada la atomización inicial y desarrollaba en aquel territorio iniciativas comunes con notoria eficacia, algo que será constante hasta la Guerra Civil (Santos Castroviejo y Nores Soliño, 2005).

Colectivos como la Asociación General de Industrias Pesqueras y Derivados tuvieron un papel principal en la superación del localismo por parte de los armadores y fabricantes organizados en la costa gallega. En concreto, con posterioridad a la Guerra Mundial se dieron pasos cara una estructuración a nivel gallego de la Patronal pesquera, quizás para responder a las federaciones regionales impulsadas por socialistas y libertarios: la constitución en Vigo bajo patrocinio de la susodicha Asociación General de un Sindicato de Armadores de Vapores Pesqueros de Galicia corriendo el mes de agosto de 1919, por ejemplo.

Una vez organizada, siquiera de manera incipiente, la Patronal pesquera galaica, la propia Asociación General ofició como referente ya desde aquel año para la creación de una Federación de Armadores de Buques de Pesca de España, consolidada en 1923 con la participación de las patronales de la pesca industrial de Barcelona (Cataluña), Pasaia, Donostia (Euskadi), Cádiz, Huelva, Málaga (Andalucía), Gijón (Asturias), Vigo-Bouzas, Marín y Coruña (Galicia). Paralelamente y también a partir de 1919, la Asociación impulsó la Federación Nacional de Industrias Pesqueras y sus Derivados, concebida como grupo de presión económico y político que incorporaba armadores, conserveros y salazoneros de 18 puertos españoles. Culminaba así una visión más estructurada y global de los intereses de clase de los principales propietarios de medios de producción en la industria pesquera y actividades asociadas a nivel estatal, conformando un interlocutor colectivo privilegiado para las negociaciones con la administración en temas considerados clave (suministro de carbón, creación de una "Mutualidad" de accidentes de trabajo, comunicaciones ferroviarias, legislación laboral, etc.) para el futuro de la industria. ${ }^{11}$

Como concluye Jesús Giráldez refiriéndose a la Asociación de Armadores de Cádiz, donde eran mayoría los de procedencia galaica:

...la Asociación de Armadores de Buques de Pesca se configura como la plasmación local de una red de empresas, pero cuyo

11. Actas del Consejo de Dirección de la Federación de Armadores de Buques de Pesca de España, 1925-1928. También Boletín de Pescas, Ministerio de Marina, Dirección General de Navegación y Pesca-Instituto Español de Oceanografia, agosto-diciembre de 1920, Madrid. 
funcionamiento supera con frecuencia ese ámbito... En definitiva, un complejo entramado empresarial que se extiende por los principales puertos, desde San Sebastián a Barcelona, y que se aglutina orgánicamente en la Federación Nacional de Armadores de Buques de Pesca. (Giráldez Rivero, 2002)

En lo sucesivo, durante el conflictivo tiempo republicano, la fijación de las bases de trabajo con los sindicatos superará en buena medida el marco local, para conformarse un espacio de negociación con ámbito estatal, muy influido por las confrontaciones que tuvieron lugar en los puertos más importantes, como Pasaia, Gijón, Cádiz, Vigo-Bouzas o Coruña. En cualquier caso, y tanto en lo referido a la Patronal como a los sindicatos marineros, en este nuevo escenario supralocal el protagonismo y el carácter pionero de los agentes sociales radicados en Galicia será muy relevante.

\section{Un nuevo impulso}

En el mes de febrero de 1930, la tragedia arribó al puerto de Bouzas: cuatro vapores parejas con sus 42 tripulantes se hundian en aguas del Grand Sole. El luto obligó al amarre de la flota y la indignación de las tripulaciones avivó las conciencias adormecidas; aprovechando el ambiente, José Villaverde y Manuel Montes convocaron una asamblea para reorganizar la Sección Flota Pesquera del Sindicato General de Trabajadores de Vigo y, asimismo, relanzar la FRGIP.

La señal del nuevo impulso societario en el mar estaba dada y en el verano ya funcionaba la organización pesquera viguesa, que agrupaba buena parte de las dotaciones de los palangreros de O Berbés y de las parejas de Bouzas, unificando en su seno las antiguas sociedades de marineros, de patrones y de fogoneros de Vigo-Bouzas e incorporando también a las mujeres que trabajaban como empacadoras. ${ }^{12}$

Para consolidar la organización pesquera de Vigo, en la Confederación Regional Galaica (CRG) de la CNT se tomó una importante decisión: el traslado como liberado a la ciudad olívica de su antiguo secretario, el carpintero compostelano Manuel Fandiño, hombre de probada capacidad negociadora y organizativa; su cometido será el de asumir la secretaría de la FRGIP. Con los sindicatos marineros de Vigo, Marin y A Coruña operando en las localidades que, además de concentrar la mayor parte de la pesca industrial del litoral, eran centros de atracción tanto de mano de obra como de las capturas procedentes de numerosas villas marineras, la Regional Pesquera ya podía dejar sentir su peso en los 
pequeños puertos. Mas para ello debía probar su fuerza frente a los armadores y, en un proceso paralelo, adaptar la estructuración interna a la compleja realidad económica y social de la pesca.

Antes de continuar, cabe un breve apunte sobre las dificultades para practicar una acción sindical estable en la pesca en general y en la de altura en particular, pues los buques o pasaban muchos dias lejos de tierra apartados unos de otros, o, en el caso de la bajura, la gente pasaba en el mar la mayoria de la jornada, en horarios en absoluto equiparables a los de los trabajadores de tierra. Estas dificultades, por lo tanto, justificaban algunas medidas ciertamente poco habituales en la CNT, como la presencia de liberados sindicales, figura normalmente muy discutida en los sindicatos confederales, opuestos a la profesionalización del sindicalismo; actuando con pragmatismo y dejando fuera aspectos doctrinales, los liberados fueron admitidos en distintas ocasiones y también en diferentes puertos, con la finalidad de que estuviesen en condiciones de atender los problemas que pudieran surgir en tierra en ausencia de los asociados que, además, generalmente elegían un delegado sindical por barco. Hay que tener en cuenta que, para realizar una asamblea donde poder discutir cuestiones de interés general, era necesario el amarre temporal de la flota pesquera en cuestión.

Retomando el relato, el control sindical del puerto pesquero vigués, el más importante del Estado junto al de Pasaia, fue la piedra de toque no solo para Galicia sino para el resto del litoral español. Así, poco antes de implantarse la Segunda República, los cenetistas reclamaron el descanso dominical, siendo despedidos varios marineros por tal motivo; en aquel instante, la Patronal pesquera rechazó tratar con el sindicato anarcosindicalista por "revolucionario", reconociendo tan solo al Montepío de Obreros del Mar, de carácter "amarillo" y confesional, como interlocutor. ${ }^{13}$

Luego, con la República ya en marcha y por iniciativa del Ministerio de Marina, tendrán lugar a nivel estatal las negociaciones entre la Federación de Armadores de Buques de Pesca de España y los sindicatos UGT y CNT, iniciadas en Madrid en torno al mes de abril de 1931 y que se prolongarán en distintas fases hasta la primavera de 1932, con las mejoras salariales, reglamentación del descanso, subsidio de enfermedad, incremento de las dotaciones y garantías en las contrataciones y despidos, como temas planteados por los colectivos marineros. Paralelamente, se van a suceder las huelgas motivadas por las referidas cuestiones en las flotas de altura radicadas en Coruña, Ferrol, Gijón, Pasaia o los puertos andaluces de Huelva o Málaga, de manera que los armadores tendrán la certeza de que había un movimiento de fondo que trascendía

13. El Pueblo Gallego, Vigo, 3/5/31. 
la problemática local. ${ }^{14}$ Según José Villaverde, uno de los representantes en liza, las reuniones de Madrid fueron más que nada una tentativa de las autoridades republicanas de cara a establecer una corriente de armonía entre los sindicatos pesqueros y la Patronal, para posibilitar un clima propicio en el que desarrollar un nuevo marco normativo de relaciones laborales. De acuerdo con el propio Villaverde, desde el inicio la Patronal se mostró reacia al diálogo en torno a la aprobación de unas bases de trabajo comunes a todo el litoral, ya elaboradas en el congreso inaugural de la anarcosindicalista Federación Nacional de Obreros de la Industria Pesquera y sus Derivados (FNIP), y prefirió tratar aisladamente los conflictos locales para que no se extendiesen las mejoras conseguidas en los puertos más combativos (Colectivo Xerminal, 1990).

En este contexto, la CNT decidió el amarre de los vapores pareja de Bouzas para el $1^{\circ}$ de Mayo de 1931, aprovechando el regreso del Grand Sole; las reivindicaciones eran las que se comenzaban a negociar en Madrid. La relativa victoria conseguida sobre una Patronal cada vez más beligerante con las disposiciones laborales de la República permitirá consolidar el sindicato tras su reconocimiento por parte de los armadores, lo que a su vez contribuirá a la conformación de un sindicalismo marinero coordinado a escala estatal. Así, se acometió la inmediata organización de la referida Federación Nacional, a lo que también ayudó la firmeza y continuidad mostrada por El Despertar Maritimo coruñés; por contra, la huelga de las parejas de Bouzas también puso de manifiesto la urgencia de reorganizar la Patronal española de la pesca de altura.

Volviendo a Bouzas, la aplicación de las nuevas bases de trabajo permitió practicar una presión en aumento sobre la contratación de los tripulantes y, de rebote, sobre la sindicación de los pescadores de otras villas que descargaban o se enrolaban en el puerto vigués, tal y como ya se practicaba hacía tiempo en Coruña. ${ }^{15}$ La integración en la CRG de sociedades marineras distribuidas por todo el litoral gallego fue progresiva a partir del verano de 1931, un momento en el que la coyuntura política favorecía al sindicalismo y era patente la expansión de la pesca semiindustrial a la mayoria de las villas costeras. Las primeras en incorporarse fueron las agrupaciones de Porto do Son, Moaña, Cangas y Bueu, la mayoría procedente de la UGT, de manera que, en breve, la CRG contará con sindicatos en casi todos los puertos del litoral gallego.

La moderación de la estrategia socialista, centrada en evitar problemas a la coalición republicano-socialista y respaldar su política

14. Revista Industrias Pesqueras, Vigo, 15/5/31.

15. Según las bases en cuestión, los armadores tenían libertad para elegir los tripulantes, siempre que estuvieran afiliados al sindicato cenetista. Además, solo se reconocía el despido procedente. 
sociolaboral reformista, tuvo bastante que ver en este cambio de relación de fuerzas. Así, el delegado de Vigo en la referida Federación del Transporte, Pesca e Industrias Marítimas de España (UGT) criticó en agosto de 1933 el hecho de abandonar la huelga de los pescadores de Baiona, llevada a cabo el año anterior; por toda respuesta, la Ejecutiva señaló que los pescadores declararan el paro sin consultar y "dieron muestras de extremismos y cometieron atentados". ${ }^{16}$ En consecuencia, el sindicato socialista quedó muy disminuido en cuanto a su afiliación entre los marineros durante el período republicano.

\section{Constitución de la Federación Nacional de Industria Pesquera y sus Derivados}

Ciertamente, la continuidad organizativa de la FRGIP resultó determinante para el referido proceso de integración. El cambio de nombre allá por 1926 (de Maritima a Pesquera) no era intrascendente: reflejaba un cambio en su concepción; ahora, los sindicatos federados acogerán solo las profesiones vinculadas a la pesca, tanto de tierra como de mar. En 1933, la visión integral de la industria se completó al incorporarse los choferes propietarios de las camionetas que trasladaban el pescado al interior, desde Coruña, Ribeira, Marin o Cariño. Estos trabajadores jugaron un rol importante a la hora de consolidar la organización cenetista en los puertos antedichos, ya que su concurso fue decisivo a la hora de disuadir posibles descargas de pescado procedentes de esquiroles. ${ }^{17}$

Durante la Segunda República, la FRGIP se domicilió primero en Vigo y luego, a partir de 1934, en Marín; en las dos localidades asumirá la secretaría Manuel Fandiño, que actuó como liberado hasta la Guerra Civil. Como se dijo, la organización marinera gallega se adelantó a la implantación de las federaciones de industria decidida por la CNT en el congreso celebrado en junio de 1931, puesto que ya en un pleno de la CRG acontecido en octubre de 1930, Montes y Villaverde defendieron la creación de la Federación Nacional de Industria Pesquera y sus Derivados (FNIP) a partir de la FRGIP, ya perfilada desde hacía tiempo en sentido industrialista. ${ }^{18}$ Así, la FRGIP fue la primera federación de industria que funcionó en Galicia y posiblemente en el Estado español. Los cuadros marineros agrupados en la CRG, asumieron la progresiva interacción existente entre los diversos puertos y la actividad cada

16. Actas de la Federación del Transporte, Pesca e Industrias Marítimas de España (UGT), 15/1/1933, Carpeta 1121, Legajo 350, Serie Madrid; Archivo Histórico Nacional, Sección Guerra Civil, Salamanca.

17. CNT, Madrid, 18/10/33.

18. Solidaridad Obrera, Coruña, 13/12/30. 
vez más diversificada de éstos, a semejanza del funcionamiento de un complejo industrial. Esta comprensión permitió una significativa implantación: alrededor de 12.500 asociados de 24 puertos en 1932 que, a 18 de Julio de 1936, ya se convirtieran en cerca de 18.000 afiliados de ambos sexos, que engrosaban sindicatos radicados en 47 puertos distribuidos por toda la costa gallega. De hecho, la CRG tuvo su mayor presencia en el sector de la pesca, que agrupaba el $43 \%$ del total de su afiliación. ${ }^{19}$

La integración de las antiguas sociedades marineras en la CNT facilitó su progresiva conversión en Sindicatos de Industria Pesquera (SIP), que distribuian los diversos oficios en las respectivas Secciones. La transformación de la Sección Flota Pesquera del Sindicato General de Trabajadores vigués en Sindicato de Industria Pesquera "Mar y Tierra" poco antes del Congreso de 1931 inició las renovaciones organizativas: primero Marín y Coruña; luego, vendría la reforma de las sociedades existentes en Cangas, Moaña, A Guarda, Ribeira..., o la creación de sindicatos de industria alli donde no existía más organización que el Pósito, como en Cambados, Celeiro, Cariño, Espasante... Los Estatutos del SIP de esta localidad, indicaban en su artículo $5^{\circ}$ que:

...estará compuesto de tantas secciones como características profesionales tenga la industria y sus similares, y el Sindicato reconocerá a cada una de ellas el derecho a tratar y resolver las cuestiones que no comprometan los intereses generales de la colectividad y cuando estos corrieran riesgo de ser comprometidos por medio de la declaración parcial o general de una huelga, la sección o secciones que se hallaran en tal caso no podrán declarar conflicto alguno sin previo conocimiento general de las demás secciones que integran el Sindicato. ${ }^{20}$

Los sindicatos pesqueros más importantes fueron el SIP "Mar y Tierra" de Vigo-Bouzas, que en 1932 contaba con 2.200 socios; el de Coruña, con 2.370 afiliados y afiliadas; el de Marín, con 1.600; La Alianza Marinera de Cangas, 1.500 , y con cifras parecidas la Solidaridad Marinera de Moaña. Como ya se apuntó, en los sindicatos anarcosindicalistas implementados en los pequeños puertos de pesca se mantuvo una apreciable presencia de pequeños armadores que patroneaban sus embarcaciones.

Consecuentemente con su experiencia, se les debe a los marineros gallegos, como ya se dijo, el impulso para la creación de la FNIP, par-

19. Ver Solidaridad Obrera, Coruña, 3/9/32; El Avance Marino, Pasaia, mayo 1936; Solidaridad Obrera, Barcelona, 5/5/36.

20. Estatutos del Sindicato de la Industria Pesquera y sus Derivados de Espasante. Archivo privado. 
tiendo de la propia organización territorial. En el proceso, tomó parte destacada el SIP de Vigo a través de su periódico Redención Maritima, editado a partir de junio de 1931 bajo la dirección de Manuel Fandiño. He ahí la tarjeta de presentación del periódico en la prensa confederal:

En él se recogerán y propulsarán las aspiraciones de los obreros de todos los Sindicatos Maritimos de España, historiando sus movimientos reivindicativos y laborando por el estrechamiento más sólido de las relaciones, a fin de consolidar cuanto antes la Federación Nacional de Obreros de la Industria Pesquera y sus Derivados, cuya iniciativa fue unánimemente acogida por los delegados de los puertos españoles reunidos el pasado mes en Madrid. ${ }^{21}$

La FNIP se creó, pues, en la capital de España el 25 de octubre de 1931, coincidiendo su congreso constituyente con la huelga de la flota de arrastre de Gijón y con el transcurso de las referidas negociaciones con la Patronal que, sin ninguna mejora efectiva, se estaban celebrando allí. En correspondencia con la implantación confederal en el litoral galaico, el primer Comité Nacional de la FNIP residió en A Coruña, ejerciendo como secretario liberado Manuel Montes, quedando la dirección del periódico Mar y Tierra a cargo de José Villaverde; en aquel momento, se declaraba una afiliación de 13.500 marineros. ${ }^{22}$ Un año más tarde, al acceder José Villaverde a la secretaría de la Confederación Regional Galaica (CRG) de la CNT, el Comité recalará en Vigo, siempre con Montes a la cabeza.

Durante todo el periodo republicano, el predominio de la organización galaica fue notorio dentro de la FNIP, pues en 1936 aquella representaba más del $40 \%$ de sus miembros y una tasa de sindicación en el litoral gallego que superaba el 30\%, mientras que la FNIP integraba en torno al 25\% de los marineros del resto del litoral español. En cualquier caso, no debe sorprendernos ni la faceta pionera en sentido organizativo, ni la importancia numérica de los trabajadores del mar gallegos, ya que la industria pesquera gallega era, con diferencia, la más desarrollada de toda la Península (Pereira, 2002).

21. Solidaridad Obrera, Coruña, 27/6/31.

22. Constitución del Comité Nacional, datada en Coruña el 23/11/1931. Oficios FNIP, Sindicato General de la Industria Pesquera, Archivo Histórico Nacional, Expedientes Policiales H-13638, 1931-1936. 


\section{Práctica sindical y respuesta de los armadores}

Las sociedades marineras anarcosindicalistas afectas a la FRGIP, caracterizadas por sus tácticas basadas en la acción directa, una gran autonomía y el rechazo al parlamentarismo, sostuvieron una marea de huelgas por toda la costa gallega, bien en puertos acostumbrados a ellas como Cangas, Moaña, Vigo, Coruña, Marín..., bien en otros en las que eran toda una novedad como Cariño, Celeiro, O Grove o Aldán.

En este período republicano, las confrontaciones en la pesca serán las más prolongadas de todos los sectores de la economía gallega, debido a la postura cerrada mostrada por la Patronal, que debía afrontar la erosión del principio de autoridad tras la debilidad de las derechas en la alborada republicana y, al tiempo, el descenso de la tasa de ganancia resultante de la tendencia a la baja de los precios del pescado y del incremento de la presión sindical por unas mejores condiciones sociolaborales. Esta intransigencia se va a poner de manifiesto en las susodichas negociaciones de Madrid, que las tácticas dilatorias ejercidas por la delegación Patronal condujeron a su fracaso más absoluto en la primavera de 1932.

Al tiempo, la propia Federación de Armadores de Buques de Pesca de España se va a reestructurar en octubre de 1931, reforzando alianzas y procurando un mayor control de los conflictos locales. Así, se aceptó la entrada de algunos gremios independientes de armadores en distintos puertos, se adoptaron medidas solidarias con los armadores implicados en huelgas y se fijaron sanciones para quien no cumpliera los acuerdos. Además, a petición de los armadores de Cádiz, el Consejo de Dirección de la Federación procedió a impartir "instrucciones a los puertos para las huelgas parciales, señalando las condiciones máximas y mínimas dentro de las que puedan resolver". ${ }^{23}$

En este clima de confrontación y reforzamiento organizativo de las partes contendientes, destacó la resistencia de los pescadores, algo en lo que tuvo mucho que ver la socorrida posibilidad de faenar durante los conflictos con pequeñas barcas y artes tradicionales propiedad de los huelguistas, su frecuente condición de propietarios de pequeñas parcelas en el litoral (Giráldez Rivero, 1996) y la solidaridad de otros puertos vehiculizada por la FRGIP. Así, en 1931, durante las huelgas de Teis, Baiona y Cangas, localidad donde 1.500 tripulantes mantuvieron las motoras amarradas durante 4 meses por discrepancias con la Patronal sobre las tareas en tierra, un total de 2.040 marineros superaron las 200.000 jornadas de trabajo perdidas, si damos crédito a los datos del

23. Actas del Consejo de Dirección de la Federación de Armadores de Buques de Pesca de España, celebrado los días 20, 22 y 25/10/1931. 
Ministerio de Trabajo, a menudo infravalorados. De hecho, no contabilizaron la llamada "folga das maquiniñas", provocada al inicio de aquel año por la pretensión de los armadores de las motoras sardineras de Moaña de retener una "parte" de la retribución de los tripulantes, para amortizar los nuevos mecanismos de virada de los aparejos del cerco. La huelga, que duró 4 meses en medio de constantes enfrentamientos entre huelguistas y esquiroles, terminó de manera positiva para la Solidaridad Marinera, debido al miedo en el cuerpo que la proclamación de la República metió en los armadores. ${ }^{24}$

En la segunda mitad del año 1932, el amarre de las parejas de Bouzas decidido por el SIP y que afectó a más de 3.000 tripulantes que reclamaban algunas cuestiones pendientes desde el año anterior en materia de descanso, incremento de las dotaciones y salarios, además de la Bolsa de Contratación gestionada por el sindicato, se demoró cinco meses (Colectivo Xerminal, 1990). El conflicto se desenvolverá en un contexto desfavorable, caracterizado por un estancamiento a la baja de los precios de las capturas, una Patronal pesquera recientemente reestructurada y las organizaciones marineras de Huelva, Málaga, Algeciras, Cádiz, Gijón y Pasaia debilitadas tras prolongadas huelgas que fueron resueltas de manera contraria a los sindicatos de clase en la mayoría de los casos.

Por tanto, tras soportar un masivo lock out (Bragado, 1933) a los dos meses de conflicto, el SIP "Mar y Tierra" de Vigo-Bouzas apenas pudo reaccionar cuando muchos armadores de Bouzas, amparados por la Federación de Armadores de Buques de Pesca de España, decidieron trasladar sus barcos al Sur de la Península tripulados por esquiroles procedentes de puertos con influencia de la UGT. En medio de violentos disturbios y a pesar de la importante solidaridad mostrada por la FRGIP, el SIP vigués perdió el control de las contrataciones en el muelle de Bouzas a manos de un sindicato inspirado por la Patronal, la Agrupación Independiente de Trabajadores de la Industria Pesquera. Así, una vez que La Marítima incumplió el laudo del delegado del Ministerio de Trabajo por el que se daba por finalizada la huelga en diciembre de 1932 previa readmisión de los afiliados al SIP despedidos, la Agrupación hizo y deshizo a su gusto en los años siguientes. Las cosas no acabaron aquí, ya que la FNIP decretó el boicot a las descargas de los barcos tripulados por esquiroles en toda la costa, medida que tan solo mantuvieron con dificultades el SIP coruñés y los sindicatos de Gijón y Pasaia. ${ }^{25} \mathrm{Y}$, quizá debido a la generalización de este conflicto, la Patronal

24. Ver Mi testamento humano y social, s.d., memorias escritas por Luis Pérez Álvarez "Nacidas", antiguo afiliado a Solidaridad Marinera de Moaña.

25. Oficios del SIP datados el 20/5/1934 y 15/9/1935. FNIP, Sindicato General de 
pesquera española decidió asumir la dirección de todas las huelgas que se presentasen en adelante. ${ }^{26}$

El desgaste sufrido por la organización viguesa tuvo dos importantes consecuencias organizativas. En primer lugar, la secretaria de la FRGIP recalará a partir de 1934 en Marín. En segundo lugar, el Comité de la FNIP marchará para Gijón a finales de 1933; la decisión se tomó en un Pleno Nacional de la Federación celebrado en Madrid el 9 de octubre de 1933. Al pleno asistieron delegaciones en representación de 11.966 afiliados a diez sindicatos pesqueros de Galicia, tres de Asturias, uno de Euskadi, otro de Andalucía y dos, que asistieron con carácter informativo, de Barcelona. La baja de afiliación en relación al congreso constituyente de la FNIP dejaba traslucir una situación de crisis, cuyas causas reflejó el comité en su Informe:

La Federación se constituyó en octubre de 1931, y desde entonces puede decirse que toda su vida se desenvolvió con conflictos entre los trabajadores de la industria y la Patronal... Es innegable que los armadores al provocar sistemáticamente a los sindicatos pesqueros lo hacian previo meditado plan para abortar la organización naciente... Interesa declarar que las huelgas tuvieron un final lejos de nuestro deseo... En estas lineas explicativas de nuestros primeros pasos en la Federación encontrareis, compañeros delegados, la causa de que no se haya conseguido mayor efectividad en la labor encomendada a los que integramos este Comité. ${ }^{27}$

Además de las duras derrotas en las huelgas de Huelva, Cádiz y Vigo, que alentaron a la Patronal para dar la callada por respuesta a las reivindicaciones de la FNIP, había otras causas que explicaban el mal estado de la organización. En primer lugar, las divisiones dentro de la CNT, escindida entre los "moderados" nucleados en torno al "Manifiesto de los Treinta" y los partidarios de una confrontación abierta con el régimen republicano, división que provocó la marcha del sindicato andaluz de Huelva y casi deshizo el propio pleno, por el choque entre los dos sindicatos de Barcelona que se reclamaban de la FNIP. Como trasfondo estaba, no obstante, la desconfianza que las federaciones de industria provocaban en no pocos confederales, que las consideraban limitativas para la autonomía de los sindicatos y caldo de cultivo de una posible

la Industria Pesquera, Archivo Histórico Nacional, Expedientes Policiales H-13638, 1931-1936.

26. Revista Industrias Pesqueras, 1/12/32.

27. "El Congreso Pesquero. Informe del Comité de la Federación Nacional", CNT, Madrid, 26/10/33. 
burocracia sindical. En este sentido, creemos que no es casual el hecho de que tanto la FRGIP como la FNIP, se gestasen en una Confederación Regional (la CRG) que se alineó mayoritariamente con los "moderados" y en apoyo de tales federaciones (Pereira, 1994).

También las tensas relaciones con los socialistas causaron múltiples trifulcas durante los conflictos. Confrontados aquéllos con las tácticas de los cenetistas y partidarios de los pactos con la Patronal a través de los organismos de arbitraje, en ocasiones reventaron los paros. Así pasó, por ejemplo, en Cádiz en otoño de 1931, con La Naval (UGT) y El Despertar Marítimo (CNT) como contrincantes, situación que se repetirá en la citada huelga de las parejas viguesas, provocando la derrota de los marineros.

Para complicar más las cosas, apareció un nuevo factor: las tentativas de los comunistas para controlar los sindicatos confederales. En Cádiz, una vez más, la presencia de El Despertar Marítimo en la organización sindical de carácter regional que intentó crear el PCE en Andalucía durante 1931 provocó que fuera expulsado de la Federación Local cenetista y situada en stand by dentro de la FNIP hasta mediados de 1932, fecha en la que se desplazó a la dirección comunista y se reintegró a la CNT (Gutiérrez Molina, 1994).

También los choques entre las diversas corrientes ideológicas (socialistas, comunistas, libertarias) operantes en el SIP "La Unión Marítima" del puerto vasco de Pasaia continuaron después de la infausta huelga pesquera de $1931 .{ }^{28}$ A lo largo del año siguiente, la FNIP envió a sus directivos más reconocidos a Pasaia para conseguir la adhesión del colectivo; así, tanto su secretario Manuel Montes como José Villaverde realizaron sendos actos de propaganda en Pasai San Pedro (Pasaia). Al final del segundo año republicano, tendrá lugar un referendum para decidir su integración, bien en la UGT, bien en la CNT. En aquel momento el secretario de la CRG y uno de los fundadores de la FNIP, José Villaverde, se mostró confiado en el resultado de la consulta por la notoria mudanza de talante que se registraba en la incesante emigración galaica a Pasaia, debido a la fuerte expansión del anarcosindicalismo entre las gentes de mar de múltiples localidades de la costa gallega. ${ }^{29}$ Pero las cosas no salieron como Villaverde esperaba, aunque en la votación los partidarios de la CNT superaron a los de la UGT: sucedió que los comunistas, defensores de la abstención, puesto que pretendian declarar autónoma a La Unión, consiguieron que los abstencionistas

28. En ese conflicto declarado para reivindicar unas bases de trabajo parecidas a las que se negociaron en Madrid, hubo que lamentar 7 muertos y 30 heridos a manos de la Guardia Civil (Pereira, 2011).

29. Solidaridad Obrera, A Coruña, 16/1/33. 
fueran considerados vencedores, dándose el colectivo de baja en la UGT sin integrarse en la CNT. Esto provocó el abandono de los libertarios y la adhesión del sindicato a la Confederación General del Trabajo Unitaria, central comunista a la que estará vinculado hasta diciembre de 1935, fecha en la que retornará a la UGT.

Por consiguiente, a principios de 1933 se constituirá el SIP "El Avance Marino" integrado en la FNIP y domiciliado en Pasai San Pedro: durante el referido pleno de la FNIP el sindicato declaró una afiliación de 599 pescadores, rederos, empleados de la pescadería y personal de la factoría de bacalao. ${ }^{30}$ De todos modos, El Avance Marino fue minoritario en relación a La Unión Marítima hasta el tramo final de la República, y sus inicios no resultaron nada sencillos debido al boicot que sus afiliados debieron sufrir por parte del sindicato comunista, que los consideraba "escisionistas".

Por último, a la FNIP tampoco le benefició la coyuntura sociopolítica al final del primer bienio republicano, porque importantes sindicatos como los de Cádiz y Pasaia tuvieron cerrado su local a partir del mes de mayo de 1933, por decisión gubernativa tras los movimientos de protesta impulsados por la CNT contra la ola represiva de que era objeto por parte del Gobierno. La persecución gubernamental interrumpió, de hecho, las tareas de propaganda del comité de la FNIP al final de su mandato, dejando éste inacabado. Como apuntaba José Villaverde desde Mar y Tierra:

Mucho se trabajó para agrupar a todos los que del mar viven en nuestros sindicatos. Pero es preciso fijar bien la atención en lo que falta por hacer. El Sur de España está casi huérfano de organización... El Mediterráneo, si bien cuenta con organización, ésta no está integrada a la Federación Nacional de Industria Pesquera... En el Cantábrico ocurre algo de lo mismo... Se ha interrumpido esta obra de propaganda y es preciso organizarla, aunque ello cueste los mayores sacrificios. Los sindicatos de Galicia y Asturias deben pensar en ello inmediatamente. (Villaverde, 1933)

Pero en Galicia la organización no estaba para muchas alegrias. Derrotas tan significativas como la sufrida en el conflicto de las parejas de Bouzas determinaron la posterior atonía de la organización viguesa, que además debió soportar las escisiones de algunas secciones a favor de la UGT y una estrategia concertada de los armadores de las rias de Vigo y Pontevedra llevada a cabo durante los años 1933 y 1934 (Colectivo Xerminal, 1990). La susodicha estrategia, consistente en debilitar

30. Solidaridad Obrera, Coruña, 25/2/33; CNT, Madrid, 9/10/33. 
los sindicatos marineros mediante la provocación de enfrentamientos derivados de posturas intransigentes, en las que el empleo del lock out y del personal revienta-huelgas fue reiterado, se aplicó alli donde los sindicatos de la FRGIP compartían espacio con la central socialista, caso de Vigo, Marín, Bueu o Cangas. En estos episodios, el abstencionismo de la UGT, la actuación de los "amarillos" y las escisiones inducidas acarrearon bien la desorganización societaria, bien la pérdida de afiliación en algunos puertos de las Rías Baixas.

En consecuencia, a finales de 1933 Asturias parecía la mejor solución para acoger al Comité de la FNIP, cuya secretaría radicó, como dijimos, en Gijón y recayó con toda probabilidad en el directivo del SIP de aquella localidad, José A. López Iturralde. Pero el itinerario astur de la Federación duró poco, pues la represión desatada tras la Revolución de Octubre de 1934 obligará a trasladar el Comité al puerto andaluz de Cádiz y allí ocupará la secretaría Julio Fernández. De todos modos, el paso de la FNIP por ambas localidades apenas dejó rastro, pues la precariedad del momento impidió continuar con la edición del periódico Mar y Tierra. En conclusión, en el otoño de 1935 la FNIP, lastrada por el poderío patronal, las divisiones y los problemas gubernativos, apenas avanzara desde su creación. Según su comité, si hubo algún crecimiento en aquel período (en Andalucía, en el Mediterráneo) se debía "al ambiente general y por los esfuerzos realizados por organizaciones ajenas a la industria". ${ }^{31}$ Aún así, la FNIP era, en competencia con la Federación del Transporte, Pesca e Industrias Marítimas (UGT), de lejos la propuesta sindical más implantada en las actividades pesqueras.

\section{Los últimos meses de la República}

La impotencia de los sindicatos cenetistas de las Rías Baixas para resolver situaciones de conflicto sin el concurso de la UGT alentó a la FRGIP en su firme defensa de las Alianzas Obreras "con finalidades concretas", postura manifestada durante el Pleno de la Federación celebrado en Santiago en el otoño de 1935. Allí, haciendo gala de un cierto pragmatismo (presente, asimismo, en la utilización sistemática de liberados y en el apoyo a la organización industrialista), diversos delegados plantearon el acuerdo con el sindicato socialista como base de la reorganización sindical en los puertos, tras la represión que siguió a la Revolución de Asturias:

Molanes, de Cangas, demuestra lo fatal de la lucha entre trabajadores, que actuando en completo desacuerdo y divorcio,

31. El Avance Marino, Pasaia, abril 1936. 
actúan desbarajustadamente, proporcionando el triunfo a las patronales. Cangas pertenece a la CNT, pero quiere que le ayuden, y por su parte ayudar a los demás en los conflictos entre el capital y el trabajo. ${ }^{32}$

Semejante posición, en un clima de apasionado debate en el interior de la CNT sobre la conveniencia de tales alianzas, es posible que originara tensiones entre la FRGIP y otros sindicatos integrados en la FNIP, que miraban con reticencia las propuestas de colaboración con la UGT. El desencuentro acaso podría explicar parcialmente la pobre presencia de la FRGIP en el II Congreso de la FNIP, celebrado en mayo de 1936 en Zaragoza, coincidiendo con el congreso de la CNT, así como las críticas de algunos delegados allí presentes acerca del presunto desinterés y del pretendido localismo demostrado en aquel momento por la organización marinera galaica, en relación a la FNIP en general y al comicio en particular. En el curso de los debates, se aprobó un voto de censura a las delegaciones ausentes, en clara referencia a la FRGIP. ${ }^{33}$ No obstante, hay que tener en cuenta no solo la desorganización imperante en Galicia y Asturias debido a la represión post-octubre de 1934, sino también la situación por la que pasaban en la primavera de 1936 los pescadores de la sardina, principal "clientela" de los sindicatos de las rías galaicas, muy afectados económicamente por su depreciación y los paros masivos que tenian lugar, para entender la disminuida asistencia gallega a la capital maña.

La celebración del Congreso de la FNIP tuvo bastante que ver con la presencia en la localidad vasca de Pasaia de un liberado muy experimentado, llamado Miguel González Inestal. De ascendencia salmantina y residencia madrileña, Inestal había participado con anterioridad en la organización del potente Sindicato de la Construcción de la capital española y en la redacción del periódico CNT (Iñíguez, 2001). En Pasaia, el salmantino asumió la secretaría del sindicato El Avance Marino, ejerciendo, además, como director de su periódico que, impreso a partir de noviembre de 1935, tomó idéntica denominación que la propia agrupación sindical. De la mano de Inestal, el vocero contribuyó a la revitalización de la FNIP, prácticamente desaparecida desde el desastre de octubre de 1934, alentando la celebración de un II Congreso que la reorganizara a fondo.

En el referido congreso, celebrado en un contexto de importante alza de la afiliación sindical tras la victoria del Frente Popular en febrero de 1936, estuvieron representados 39.260 afiliados, tres veces más que

32. Solidaridad, Coruña, 5/10/35.

33. El Avance Marino, mayo de 1936. 
en la fecha de constitución de la FNIP. Por el momento se mantenía el predominio galaico, pero ahora matizado por el importante crecimiento de los sindicatos andaluces (que sobrepasaban el 30\% de la afiliación) y la expansión de la organización pesquera confederal por el Cantábrico, Levante, Catalunya y Canarias.

El evento retomó cuestiones ya acordadas en comicios anteriores y que no habian podido ser puestas en práctica debido a la azarosa trayectoria de la FNIP, como agrupar los sindicatos marineros del conjunto del litoral en regionales, a imagen y semejanza de la FRGIP, y la unificación de las bases de trabajo para la pesca de arrastre. Así, si los armadores no respondian positivamente a partir del 15 de julio, la FNIP llamaría el 1 de agosto de 1936 al amarre de toda la flota industrial. ${ }^{34}$ Finalmente, el congreso determinó que el Comité de la Federación retornase a Vigo, ocupando una vez más la secretaría el pescador astur López Iturralde.

En correspondencia con lo decidido, una semana antes del golpe militar se constituyó la Federación Cantábrica de la Industria Pesquera en congreso celebrado en Santander, impulsado por El Avance Marino. En el evento participaron sindicatos vascos (Pasaia, Erandio, Bermeo), astures (Candás, Avilés, Gijón, Cudillero, Luarca) y santanderinos (Santoña, Laredo, Santander) en representación de 5.706 afiliados. Allí, se decidió trabajar por la integración de los Pósitos en la CNT, si bien deslindados de los sindicatos que velarian por su orientación exclusivamente cooperativa. Al fin y al cabo, la guerra impidió que el Comité pudiera residir en Pasaia. ${ }^{35}$

En Bouzas, el SIP recuperó de manera fugaz su pulso con la Patronal de las parejas a partir de mayo de 1936, contando ahora con el apoyo de la UGT. Entonces, los anarcosindicalistas exigieron de La Marítima el reconocimiento del sindicato, el despido de los antiguos esquiroles embarcados y su sustitución por los confederados y retomaron la reivindicación de la Bolsa de Trabajo controlada sindicalmente. Una vez solventadas estas cuestiones y en paralelo al puerto cántabro de Santander y las localidades andaluzas de Algeciras y Cádiz, el SIP "Mar y Tierra" intentó plantear algunos temas pendientes de la huelga de 1932, como el descanso o las vacaciones retribuidas para absorber los parados. ${ }^{36}$ Por este motivo organizó el amarre de las parejas a principios de junio, una

34. El Avance Marino, marzo de 1936.

35. "CNT-AIT. F.N.I.P. Federación Cantábrica de la Industria Pesquera. Actas y Resoluciones del Congreso Constitutivo celebrado en Santander los días 12 y 13 de Julio de 1936", CNT (España) Archives, 68 B.4, Internationaal Instituut voor Sociale Geschiedenis, Amsterdam.

36. Revista Industrias Pesqueras, 15/5/36. 
situación que se extendió hasta el albor de la Guerra Civil debido a las maniobras dilatorias de los armadores, más interesados en prolongar los conflictos locales para así boicotear la previsible presentación de las nuevas bases de trabajo con carácter general aprobadas por la FNIP y que se pretendian negociar otra vez con la Patronal española. ${ }^{37}$

Otro tanto sucedió en Pasaia, donde se quiso cambiar las bases pactadas en 1933 aprobando otras más avanzadas. En La Herrera el paro de la flota de arrastre se inició el 20 de junio, antes de lo fijado por la FNIP al ser una decisión compartida con la UGT y los Solidarios Vascos. En línea con lo decidido en el Congreso, solicitaban los marineros 300 pesetas por mes, Bolsin de Trabajo, incremento de las dotaciones, cumplimiento de los descansos, un mes de vacaciones pagadas, mejores condiciones de seguridad... ${ }^{38} \mathrm{El}$ paro llegará hasta el 18 de julio, debido a la postura cerrada de la Patronal.

Ante la sucesión de conflictos en la pesca de altura, el Gobierno del Frente Popular organizó en Madrid mediado junio de 1936 una Conferencia para discutir la situación laboral de la pesca de arrastre, convocándose por parte de los trabajadores a la FNIP, a la minoritaria Federación de la UGT y a la Federación Española de Oficiales de Marina Civil; por la Patronal fue llamada la Federación de Armadores. En medio de mutuas acusaciones de boicoteo, la Conferencia fracasó, haciéndole llegar los armadores al Gobierno la imposibilidad de aplicar las mismas bases de trabajo en todos los puertos. ${ }^{39}$ En esta situación de bloqueo, llegó la Guerra Civil.

\section{Coda}

Aún con su especial idiosincrasia y con una autonomía prácticamente total, los marineros de la CRG se incorporaron plenamente a la dinámica del proletariado sindicado en tierra. En la FRGIP participaba un grupo de cuadros experimentados, cuya preparación no solo sostuvo a los sindicatos marineros en una etapa donde la conflictividad en la pesca llegó a cotas muy altas, sino que jugó un papel destacado en el visible pragmatismo de la Confederación Regional Galaica de la CNT; he ahí su decisión en torno a las Alianzas Obreras, que servirá de precedente a la que adoptará la CRG en su congreso celebrado a

37. Causa 1415-37, Archivo del Tribunal Militar IV, Marina; Circular $n^{\circ} 3$ de la FNIP, fechada en Vigo el 7/7/1936 y Revista Industrias Pesqueras, 1/6/36.

38. "Los Sindicatos de la Industria Pesquera de Pasajes a todos los trabajadores, a la opinión pública", Solidaridad, Coruña, 4/7/36; también El Avance Marino, abril 1936.

39. Revista Industrias Pesqueras, 15/6/36. 
finales de 1935 (Pereira, 1994). En este sentido, el anarcosindicalismo marinero, potente en una región subdesarrollada y periférica como $\mathrm{Ga}$ licia, influyó de manera decisiva en el hecho de que la CRG tuviese una implantación sorprendente (más de 40.000 afiliados y afiliadas en 1936) para un territorio cuya abrumadora mayoría social estaba compuesta por pequeños propietarios rurales, refractarios en buena medida a los sindicatos de clase.

En definitiva, los marineros gallegos fueron pioneros en la peculiar conformación identitaria de la FNIP que, a pesar de su dificultoso itinerario y de las especiales características de la acción sindical en el mar, fue la única federación de industria de la CNT que existió en la práctica durante toda la República, reforzando su singularidad el hecho de que su implantación y organismos representativos estuvieran fuera de los principales "nodos" confederales, caso de Cataluña, Levante, Aragón y, de manera parcial, Andalucía. En este tiempo, la FNIP se dotó de estructuras y estrategias específicas dentro de la Confederación, pues fue uno de los pocos organismos que contó antes de la Guerra Civil con "liberados" o rentados sindicales y alentó, por ejemplo, la incorporación de pequeños armadores y transportistas. En paralelo, la FNIP, en perpetua confrontación con la gran Patronal pesquera y conservera, intentó regular y homogeneizar las relaciones laborales en la pesca industrial en todo el litoral español antes de la Guerra Civil, procurando superar las dinámicas localistas. Por último, durante el Frente Popular y con una trayectoria interrumpida bruscamente por la contienda, la FNIP se extendió a partir de su reducto galaico y consiguió una significativa presencia en toda la costa española, siendo la organización más representativa del sindicalismo de clase en el mar.

\section{Referencias}

Ansola Fernández, A. (2007), "Una pesca feliz: Alfredo Saralegui y sus Pósitos de Pescadores (1915-1936)", Historia Social, $n^{\circ}$ 57, Valencia: UNED.

Bar, A. (1981), La CNT en los años rojos: del sindicalismo revolucionario al anarcosindicalismo (1910-1926), Madrid: Akal.

Barkham Huxley, M. y E. López Losa (1999), "Pasajes, puerto pesquero", en AA.VV., Pasaia. Memoria histórica y perspectivas de futuro, Donostia: Untzi Museoa-Museo Naval, 1999.

Bragado, D. (1933), Derivaciones y consecuencias del locaut pesquero de Vigo, epílogo de Manuel Montes, Vigo: FRGIP.

Carmona, X. (1998), "Igualdade e desigualdade nas pesquerías galegas do século XVIII", Grial, n 102, Vigo: Galaxia.

Colectivo Xerminal (1990), "Crise económica e loitas sociais na Galicia republicana: o conflito pesqueiro vigués de 1932”, en AA.VV., O movemento obreiro en Galicia: catro ensaios, Vigo: Xerais. 
Delgado Cendagortagalarza, A. (1998), Bermeo en el siglo XX: politica y conflicto en un municipio pesquero vizcaino (1912-1955), San Sebastián: Eusko Ikaskuntza-Sociedad de Estudios Vascos.

Filgueira Valverde, J. (1946), Archivo de Mareantes, Pontevedra: Instituto Social de la Marina.

Giráldez Rivero, J. (1984), “El movimiento obrero en Vigo, 1890-1914”, tesis de licenciatura inédita, Universidade de Santiago.

- (1989), "Aproximaçom ao sector pesqueiro galego no primeiro terço do século XX", Agália, monográfico nº 2.

- (1996), "Crecimiento y transformación del sector pesquero gallego (18801936)", Madrid: MAPA.

- (2002), "Armadores de Cádiz: competir y cooperar", Revista de Historia Agraria, $\mathrm{n}^{\circ}$ 28, Universidad de Murcia.

González Laxe, F. (1977), Estrutura da pesca costeira galega, Vigo: Galaxia.

Gutiérrez Molina, J.L. (1994), Crisis burguesa y unidad obrera. El sindicalismo en Cádiz durante la Segunda República, Madrid: FAL.

Íñiguez, M. (2001), Esbozo de una Enciclopedia histórica del anarquismo español, Madrid: FAL.

Maná, O. (1994), "La Pêche et les pecheurs à Marin (1770-1915)", tesis de maestría inédita, Besançon: Université de Franche-Comté.

Pereira, D. (1994), A CNT na Galicia (1922-1936), Santiago: Laiovento.

- (2002), "Proletariado e loita de clases na Galiza de anteguerra", en G. Constenla Bergueiro y L. Dominguez Castro (eds.), Tempos de sermos. Galicia nos séculos contemporáneos, Universidade de Vigo.

- (2011), Loita de clases e represión franquista no mar (1864-1939), Xerais, Vigo.

Santos Castroviejo, I. y A. Nores Soliño (2005), Historia de Cangas, 19001936. Unha ribeira de pescadores, Vigo: A Nosa Terra.

Villaverde, J. (1933), “Apuntes. Los Sindicatos y Federaciones de Industria como valores constructivos", en Mar y Tierra, Vigo, 10 de junio.

Zamora Terrés, J. (2003), Notas para una historia del movimiento obrero en la marina mercante española, Museu Maritim de Barcelona.

$$
* * *
$$

Sinopsis: Tomando como hilo conductor del discurso la evolución del modo de producción de la pesca en Galicia, principal zona pesquera de la Península Ibérica, se pretende analizar el surgimiento y la trayectoria del asociacionismo marinero, en sus dos variantes patronal y obrera, asi como la consiguiente conflictividad social y laboral desarrollada en el litoral gallego, durante el período comprendido desde finales del siglo XIX hasta el golpe militar del 18 de Julio de 1936. El itinerario de las respectivas agrupaciones de marineros y armadores gallegos tuvo, además, una influencia decisiva tanto en la conformación de un espacio de relaciones laborales para todo el sector pesquero español de 
carácter industrial, como en la aparición y consolidación de organizaciones de clase con ámbito estatal, integradas las de carácter obrero fundamentalmente en la CNT.

Palabras clave: pesca - asociacionismo - conflictividad - CNT

\begin{abstract}
This paper analyzes the evolution of the mode of production of fisheries in Galicia, the main fishing area of the Iberian Peninsula, and deals with the emergence and trajectory of sailors' and ship-owners' associations and the resulting social conflict that took place in the Galician coast, from the late nineteenth century until the military coup of 18 July 1936. The development of sailors' and ship-owners' organizations in Galicia contributed to shape labor relations in the entire Spanish industrial fishing sector and helped consolidate class organizations at the national level, as most sailor unions grouped around the CNT.
\end{abstract}

Keywords: fisheries - associations - social conflict - CNT

Recepción: 6 de julio de 2012. Aprobación: 7 de septiembre de 2012 . 